\title{
O FAZER MATEMÁTICA NO ENSINO FUNDAMENTAL: UMA APROXIMAÇÃO NO CONTEXTO DA MODELAGEM MATEMÁTICA
}

\section{HACIENDO MATEMÁTICAS EN EDUCACIÓN PRIMARIA: UNA APROXIMACIÓN EN EL CONTEXTO DEL MODELADO MATEMÁTICO}

\section{DOING MATHEMATICS IN ELEMENTARY SCHOOL: AN APPROACH IN THE MATHEMATICAL MODELING'S CONTEXT}

\author{
COSTA, Daniana de \\ danianadecosta@yahoo.com.br \\ Escola Básica Municipal Irmã Cecília \\ http://orcid.org/0000-0002-8523-6156 \\ TEIXEIRA, Edival Sebastião \\ edival@utfpr.edu.br \\ UTFPR - Universidade Tecnológica Federal do Paraná \\ http://orcid.org/0000-0002-0712-8109
}

\begin{abstract}
RESUMO A aprendizagem de conceitos científicos não ocorre de modo espontâneo. Cabe à escola organizar momentos nos quais os estudantes sejam colocados em situações de aprendizagem para manejar tais conceitos. O artigo tem por objetivo apresentar e discutir a hipótese de que a modelagem matemática se constitui como uma estratégia adequada para colocar 0 estudante em atividade. Mais especificamente, propõe-se que a modelagem matemática pode promover a atividade do estudante, levando ao desenvolvimento de processos psicológicos dirigidos à criação de sentidos e à motivação para a aprendizagem nos anos iniciais e finais do ensino fundamental. Para apoiar a argumentação, é relatada uma pesquisa em que essa estratégia foi utilizada com estudantes do $9^{\circ}$ ano de uma escola de São Lourenço do Oeste, Santa Catarina.
\end{abstract}

PALAVRAS-CHAVE: Ensino e aprendizagem. Modelagem Matemática. Práticas pedagógicas. Situação de aprendizagem.

RESUMEN El aprendizaje de conceptos científicos no ocurre espontáneamente. Depende de que la escuela organice momentos en que los estudiantes se colocan en situaciones de aprendizaje para manejar tales conceptos. El artículo tiene como objetivo presentar y discutir la hipótesis de que el modelado matemático constituye una estrategia apropiada para poner al estudiante en actividad. Más específicamente, se propone que el modelado matemático puede promover la actividad del estudiante, lo que lleva al desarrollo de procesos psicológicos destinados a la creación de significados y la motivación para el aprendizaje en los primeros y últimos grados de la escuela primaria. Para apoyar el argumento, se informa una investigación en la que se utilizó esta estrategia con estudiantes de noveno grado de una escuela en São Lourenço do Oeste, Santa Catarina.

PALABRAS CLAVE: Enseñanza y aprendizaje. Modelado Matemático. Prácticas pedagógicas. Situaciones de aprendizaje. 
Atos de Pesquisa em Educação - ISSN 1809-0354

Blumenau, v.14, n.3, p.1208-1226, set./dez. 2019

DOI: http://dx.doi.org/10.7867/1809-0354.2019v14n3p1208-1226

\begin{abstract}
The learning of scientific concepts does not occur spontaneously. The school should organize moments in which students are placed in learning situations to handle such concepts. The objective is to present and discuss the hypothesis that mathematical modeling constitutes an adequate strategy to put the student in activity. More specifically, it is proposed that mathematical modeling can promote student activity, leading to the development of psychological processes aimed at creating meaning and motivation for learning in the initial and final years of Elementary School. To support the argumentation, it is reported a research in which the strategy was used with 9th year's students of a school in São Lourenço do Oeste, Santa Catarina, Brazil.
\end{abstract}

KEYWORDS: Teaching and learning. Mathematical Modeling. Pedagogical practices. Learning situation.

\title{
1 INTRODUÇÃO
}

A modelagem matemática faz parte de um conjunto de tendências no contexto da educação matemática, o qual visa proporcionar a estudantes aulas mais motivadoras e produtivas, por meio de uma situação de atividade.

Neste trabalho a situação de atividade - ou, simplesmente, atividade - é compreendida como os processos psicológicos caracterizados por procedimentos que se dirigem ao objeto, com a intenção de estimular o sujeito a executar a atividade. (LEONTIEV, 2001). Em conformidade com Bustamante (2016), a concepção de atividade, sob a perspectiva de Leontiev, tem um sentido físico e mental, pois a atividade é mediada pela reflexão mental com o objetivo de orientar o sujeito no mundo real.

Ressaltamos que, nesse caso, o conceito de atividade "[...] não significa que os alunos estejam ocupados em alguma tarefa escolar, mas sim que eles, em interação com o mundo, participem coletivamente na produção e reprodução do conhecimento". (BUSTAMANTE, 2016, p. 45). Moura (2018), explica que se trata de ações planejadas e com um motivo. Por conseguinte, concorda-se que a prática pedagógica deva promover a atividade do estudante por meio de um motivo especial (MOURA et al., 2010), o qual pode ser oriundo da realidade do estudante, de alguma temática que lhe desperte o interesse ou, ainda, sua curiosidade. 
Atos de Pesquisa em Educação - ISSN 1809-0354

Blumenau, v.14, n.3, p.1208-1226, set./dez. 2019

DOI: http://dx.doi.org/10.7867/1809-0354.2019v14n3p1208-1226

No que tange ao processo ensino e aprendizagem de matemática nos anos iniciais do ensino fundamental, Moretti e Souza (2015) afirmam que o fato de a criança utilizar a contagem, as medidas ou as formas geométricas no seu cotidiano não implicam a apropriação teórica do número ou a existência da consciência da estrutura do sistema de numeração decimal. Por outra parte, essas autoras entendem que, quando a criança utiliza os conceitos matemáticos no seu dia a dia, ou seja, nas práticas sociais, tais conceitos são significados socialmente, favorecendo a externalização e a materialização da aprendizagem.

Diante disso, é importante que o professor, na sua prática pedagógica, considere a interdependência existente entre o processo de alfabetização ou letramento matemático e o seu uso nas práticas e situações sociais. Nesse sentido, Moretti e Souza (2015) se apoiam na teoria de Vigotski para explicar que, nas práticas sociais, a consciência do sujeito está focada no contexto de utilização dos conceitos, ao passo que, na apropriação dos conceitos científicos, a consciência está voltada, intencionalmente, para o conceito. Elas exemplificam, por meio de uma situação relacionada ao ensino de grandezas e medidas, no seu uso em receitas culinárias. $\mathrm{O}$ fato de a criança utilizar diferentes unidades de medidas (colher, xícara, copo, etc.) no preparo de uma receita culinária não permite a apropriação do conceito de média, apesar de favorecer uma aproximação com unidades de medidas não padronizadas. Logo, o foco da ação da criança foi o preparo da receita, cuja abordagem é o conceito cotidiano.

A aprendizagem dos conceitos científicos não ocorre de modo espontâneo, assim, cabe à escola organizar situações de ensino nas quais as crianças são colocadas em condições cujas resoluções necessitam dos conceitos a serem ensinados. Além disso, tais situações devem estar na direção da abstração, pelo fato de superarem a superficialidade do contexto e a exploração de características dos conceitos. (MORETTI; SOUZA, 2015). Isto implica a apropriação conceitual, a qual, por sua vez, permite o uso consciente dos próprios conceitos, dando assim, autonomia em seu uso, de modo que o processo de ensino deve propiciar a passagem da atividade espontânea para a dirigida para o objetivo. 
Atos de Pesquisa em Educação - ISSN 1809-0354

Blumenau, v.14, n.3, p.1208-1226, set./dez. 2019

DOI: http://dx.doi.org/10.7867/1809-0354.2019v14n3p1208-1226

Por conseguinte, na concepção de Moretti e Souza (2015), a aprendizagem ocorre em atividade, em movimento, em ação. Assim, na perspectiva dessas autoras, a criança se apropria dos conhecimentos matemáticos no fazer matemática, ou seja, em atividade.

Moura et al. (2010), afirmam que a prática docente deve gerar e promover a atividade do estudante, criando nele um motivo especial para a sua atividade. Posto isto, para esses autores a ação do professor no processo ensino e aprendizagem precisa criar no estudante a necessidade dos conceitos matemáticos.

Justino (2013), por sua vez, discorre que, nas atividades propostas pelo professor aos estudantes, nem sempre o motivo responde à necessidade criada pelo estudante para que o mesmo seja direcionado a realizar o que the foi proposto. Visto que as ações são estimuladas pelo motivo, então, nem sempre as ações e operações desenvolvidas pelo sujeito serão satisfatórias. A autora esclarece que, "[...] dentro da atividade ocorre um movimento de transformação constante, pois quando uma atividade perde seu motivo ela se transforma em ação, porém se a ação adquire um motivo que a direcione, ela se transforma em uma atividade". (JUSTINO, 2013, p. 82).

Ainda para essa autora, a atividade pode ser compreendida pelas composições das dimensões teórica e prática, sendo que, na dimensão teórica está o motivo, o objetivo, o plano de ação e a escolha de instrumentos. Já na dimensão prática estão as ações, operações e objetos de atividades.

Visto que os estudantes se apropriam do conhecimento matemático, no fazer matemática, na ação, na relação do sujeito com o meio físico e social, então se verifica na modelagem uma possibilidade para permitir que o estudante esteja em situação de atividade em ambas as etapas do ensino fundamental. Alguns pesquisadores sugerem que a modelagem matemática (modelagem) seja inserida já nos primeiros anos da escolaridade dos estudantes, a fim de que crenças anteriores sobre a matemática sejam modificadas, ou seja, que as crenças das crianças sobre a matemática sejam consolidadas sob outro prisma (LUNA; SOUZA; SANTIAGO, 2009) e, sobretudo porque "[...] a modelagem contribui para o desenvolvimento de competências matemáticas, desencadeando a retenção de tópicos matemáticos e, 
Atos de Pesquisa em Educação - ISSN 1809-0354

Blumenau, v.14, n.3, p.1208-1226, set./dez. 2019

DOI: http://dx.doi.org/10.7867/1809-0354.2019v14n3p1208-1226

como consequência, a construção do conhecimento na área". (TORTOLA; ALMEIDA, 2013, p. 624).

Dessa forma, entende-se que a utilização de conceitos matemáticos mediante a modelagem nas práticas pedagógicas favorece a externalização e a materialização da aprendizagem da matemática pelos estudantes. A modelagem, por sua vez, pode ser compreendida como o processo de construção de modelos matemáticos no processo ensino e aprendizagem os quais podem constituir-se como um conjunto de símbolos e relações matemáticas que traduzem o fenômeno ou situação da realidade que está em investigação (BIEMBENGUT; HEIN, 2011).

Segundo Quartieri e Knijnik (2012), a modelagem foi introduzida nas escolas na década de 1980, por assinalar maior interesse do estudante pela matemática, mostrar o uso da matemática em situações-problema, desenvolver a autoestima, criticidade, responsabilidade, criatividade, liberdade para raciocinar, maior envolvimento, desenvolvimento afetivo e cognitivo dos discentes.

Existem diversas perspectivas e denominações para a modelagem. Segundo Barbosa (2001), ela é compreendida como um ambiente de aprendizagem, cuja expressão está relacionada com toda atividade escolar em que são oferecidas condições sob as quais o estudante é convidado a atuar, "[...] um ambiente de aprendizagem no qual os alunos são convidados a indagar e/ou investigar, por meio da matemática, situações provenientes de outras disciplinas ou do dia a dia". (SANTANA; BARBOSA, 2012, p. 993).

Além disso, Barbosa (2001) classificou o uso da modelagem em sala de aula em três casos, ou seja, "três regiões de possibilidades" de acordo com as limitações e possibilidades oferecidas pelo contexto escolar. No caso 1, o professor apresenta a situação-problema com os dados já coletados, cabendo aos estudantes o processo de resolução. No caso 2, o professor apresenta a situação-problema, cabendo aos estudantes a coleta de dados e o processo de resolução. No caso 3, os estudantes formulam a situação-problema a partir de temas não matemáticos, coletam dados e procedem com a resolução.

Ao utilizar a modelagem na prática pedagógica "[...] trata-se de uma "maneira" de trabalhar com atividades na aula de Matemática". (ALMEIDA; SILVA; VERTUAN, 
Atos de Pesquisa em Educação - ISSN 1809-0354

Blumenau, v.14, n.3, p.1208-1226, set./dez. 2019

DOI: http://dx.doi.org/10.7867/1809-0354.2019v14n3p1208-1226

2012, p. 17). Esses autores descrevem uma atividade de modelagem por meio de "[...] uma situação inicial (problemática), de uma situação final desejada (que representa uma solução para a situação inicial) e de um conjunto de procedimentos e conceitos necessários para passar da situação inicial para a situação final" (ALMEIDA; SILVA; VERTUAN, 2012, p. 12) sendo que os procedimentos necessários para chegar à situação final são a inteiração, momento em que o estudante entra em contato com a situação problema de maneira direta ou indireta por meio da coleta de dados; matematização, processo em que há a transformação da situação problema da linguagem natural para a linguagem matemática; resolução, ou seja, construção do modelo matemático; e , por fim, interpretação de resultados e validação em que são analisadas as respostas obtidas para o problema em diferentes contextos.

Tortola e Almeida (2013) relatam uma atividade de modelagem implementada em uma turma de $4^{\circ}$ ano dos anos iniciais do ensino fundamental, cujo problema foi: Quantos alunos cabem na sua sala de aula? Para resolvê-lo, o professor explicou o que é unidade de medida metro quadrado $\left(\mathrm{m}^{2}\right)$ e a sala de aula foi medida pelos estudantes com o uso de trena e fita métrica. Eles fizeram desenhos para representar a sala de aula, calcularam a área, e, a partir da informação "cada estudante tem direito a uma área de $1 \mathrm{~m}^{2}$ ", solucionaram o problema. Por meio dessa atividade, foi abordado o cálculo de área e as quatro operações com números decimais. Os modelos obtidos foram representações numéricas e figurais.

A outra atividade realizada com essa turma foi sobre o gasto com energia elétrica. Foram propostos problemas tais como: Qual é o seu desenho favorito? Quanta energia elétrica você gasta para assistir este desenho? Quanto é pago por isso? Para a resolução, os estudantes foram organizados em grupos, utilizaram calculadoras e extraíram informações da fatura residencial de energia elétrica. $O$ modelo obtido faz uso da linguagem numérica e foi abordada a multiplicação de números decimais.

Silva (2016) discorre sobre o trabalho de Gasperin (1990), no qual os estudantes, após terem visitado um zoológico, resolveram buscar informações sobre a alimentação de alguns animais que viviam naquele espaço. Eles pesquisaram a 
Atos de Pesquisa em Educação - ISSN 1809-0354

Blumenau, v.14, n.3, p.1208-1226, set./dez. 2019

DOI: http://dx.doi.org/10.7867/1809-0354.2019v14n3p1208-1226

quantidade de alimentos e o custo. Foram abordadas as unidades de medida, operações com números decimais e o sistema monetário.

Silva (2016) também cita Brautigam (2001), em que foi trabalhado o tema Gato, a partir da poesia Pé de Gato. Os conteúdos matemáticos abordados foram unidades de medida de massa a partir da alimentação dos animais, sistema monetário a partir da alimentação e despesas com gatos, porcentagem para o cálculo das raças de gatos e gráficos.

Frente à apresentação dessas práticas pedagógicas, conjecturamos que "[...] 'a mola propulsora', caracterizada como motivo na Teoria da Atividade [...]" (ALMEIDA; FERRUZZI, 2011, p. 5) pode estar relacionada com a temática contida em cada dessas práticas de modelagem (quantidade de estudantes que cabem na sala de aula, gasto com energia elétrica, alimentação dos animais do zoológico e alimentação, e despesas com gatos), o que acabou despertando a curiosidade do estudante ou que gerou nele uma preocupação com o objeto em investigação. Desse modo, as crianças foram colocadas em situações cujas resoluções necessitaram dos conceitos matemáticos a serem ensinados ou criaram nelas a necessidade destes conceitos (MOURA et al., 2010), por conseguinte é oportunizado à criança a apropriação dos conhecimentos matemáticos, mediante o fazer matemática, ou seja, em atividade. (MORETTI; SOUZA, 2015).

Considerando que a matemática não pode ser assimilada apenas por uma simples transmissão verbal ou constatação da realidade externa (LOPES et al., 2012), nesse sentido, apenas a transmissão verbal do conhecimento matemático não garante a aprendizagem.

Diante disso, há a necessidade de refletir sobre as práticas pedagógicas utilizadas no processo ensino e aprendizagem dessa disciplina, de tal maneira que, em acordo com Lopes et al. (2012), sejam oferecidas condições para que o estudante seja construtor do seu próprio conhecimento.

Este artigo visa contribuir para a ampliação da discussão e reflexão do uso da modelagem na prática docente, bem como no processo ensino e aprendizagem da matemática. Mais especificamente, propomos, na forma de hipótese, que modelagem na prática pedagógica pode promover a atividade do estudante, levando 
Atos de Pesquisa em Educação - ISSN 1809-0354

Blumenau, v.14, n.3, p.1208-1226, set./dez. 2019

DOI: http://dx.doi.org/10.7867/1809-0354.2019v14n3p1208-1226

ao desenvolvimento de processos psicológicos dirigidos à criação de sentidos e à motivação para a aprendizagem nos anos iniciais e finais do ensino fundamental. Para apoiar nossa argumentação, relatamos uma pesquisa em que essa estratégia foi utilizada com estudantes do $9^{\circ}$ ano do Ensino Fundamental de uma escola do município de São Lourenço do Oeste, Santa Catarina.

\section{USO DA MODELAGEM MATEMÁTICA NO $9^{\circ}$ ANO DO ENSINO FUNDAMENTAL: UM RELATO DE PESQUISA}

A pesquisa relatada foi realizada com 79 estudantes pertencentes a quatro turmas do $9^{\circ}$ ano do ensino fundamental da Escola Básica Municipal Irmã Cecília, localizada na zona urbana de São Lourenço do Oeste - SC, na qual a professora de matemática atuou, também, como pesquisadora. O protocolo de pesquisa foi aprovado por Comitê de Ética em Pesquisa envolvendo Seres Humanos.

O processo investigativo consistiu no desenvolvimento de práticas pedagógicas subsidiadas pela modelagem sob a perspectiva de ambiente de aprendizagem (BARBOSA, 2001), sendo que, para a construção dos modelos matemáticos, foram consideradas as fases propostas por Almeida, Silva e Vertuan (2012).

Para dar início às atividades de modelagem, os estudantes assistiram ao documentário A História das Coisas ${ }^{1}$. A partir da informação "[...] desapareceram $80 \%$ das florestas originais do planeta, só na Amazônia perdemos 2000 árvores por minuto, o equivalente a um campo de futebol por minuto [...]" (TIDES FOUNDATION, 2007) foi desenvolvida a primeira atividade de modelagem, conforme caso 1, cujo objetivo foi introduzir a noção de função.

Foi observado que os assuntos tratados nesse documentário, tal como, exploração dos recursos naturais para o abastecimento da indústria e o consumo/descarte exagerado de bens materiais gerou reflexão, preocupação, interesse e discussões entre os estudantes, visto que a problemática abordada no documentário permeia a realidade deles. Surgiram os seguintes comentários dos alunos:

\footnotetext{
${ }^{1}$ Este documentário foi lançado em 2007 pela ambientalista norte-americana Annie Leonard.
} 
Atos de Pesquisa em Educação - ISSN 1809-0354

Blumenau, v.14, n.3, p.1208-1226, set./dez. 2019

DOI: http://dx.doi.org/10.7867/1809-0354.2019v14n3p1208-1226

"O espaço verde, natureza, é muito importante e grande parte deste espaço some muito a cada dia que passa" (Estudante 1, E1).

"Estamos acabando com o meio ambiente" (E2).

"Nós, seres humanos, estamos utilizando uma quantidade muito grande de matéria prima" (E3).

"O problema da Amazônia afeta a vida no Planeta, portanto, todos nós. Todos perdem na qualidade de vida e apenas uma minoria ganha financeiramente" (E4).

Nesse sentido, inferimos que a temática motivou o estudante, colocando-o em situação de atividade. Por conseguinte, o motivo mobilizou o estudante, ou seja, o colocou em ação. Conforme Moura et al. (2010), a prática pedagógica promoveu a atividade dele por meio de um motivo especial, ou seja, por meio de uma temática que lhe despertou o interesse ou pelo fato deste assunto ser da realidade do estudante.

Após as discussões, na fase da interação, o problema delimitou-se a analisar a quantidade de árvores perdidas, bem como a área destruída, de acordo com a variação do tempo em diferentes unidades de medida, além de estimar a quantidade de tempo para a destruição da cobertura de Floresta Amazônica brasileira, considerando a área remanescente até 2014.

Mesmo com o auxílio da professora pesquisadora, em todas as atividades de modelagem os participantes da pesquisa puderam construir os modelos em grupo (Figura 1).

Figura 1 - Estudantes resolvendo atividade de modelagem em grupo. ${ }^{2}$

\footnotetext{
${ }^{2}$ A publicação de imagens com estudantes foi autorizada pelos respectivos pais ou responsáveis legais, bem como pelos próprios participantes da pesquisa, conforme consta no Termo de Consentimento Livre e no Termo de Assentimento Livre e Esclarecido do protocolo de pesquisa aprovado pelo Comitê de Ética em Pesquisa que analisou o projeto.
} 
Atos de Pesquisa em Educação - ISSN 1809-0354

Blumenau, v.14, n.3, p.1208-1226, set./dez. 2019

DOI: http://dx.doi.org/10.7867/1809-0354.2019v14n3p1208-1226

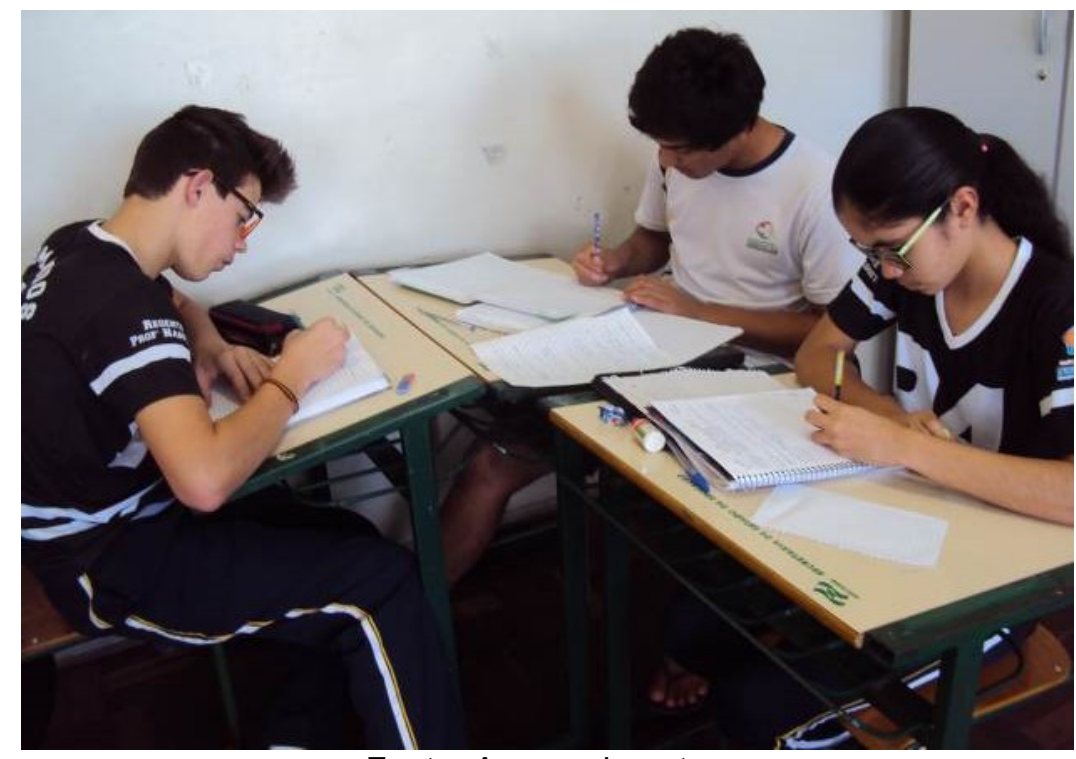

Fonte: Acervo do autor.

Na matematização e resolução foi estabelecida a hipótese de que é possível estabelecer a relação entre a quantidade de árvores perdidas e o tempo, assim, foram definidas variáveis para o tempo e quantidade de árvores perdidas.

As informações sobre a área de um campo de futebol padrão Fifa e território remanescente coberto por floresta na Amazônia brasileira em 2014 foram coletadas pela professora.

$\mathrm{Na}$ interpretação dos resultados e validação foi verificado que, apesar da área que representa a quantidade de árvores perdidas por ano estar abaixo da menor taxa de desmatamento da Floresta Amazônica registrada no período de 1988 até 2015, de acordo com esse ritmo de destruição, chegou-se à conclusão de que há a possibilidade de desaparecimento da Floresta, assim como outras florestas nativas que já desapareceram.

$\mathrm{Na}$ atividade subsequente, caso 1, o processo de modelagem iniciou-se a partir da informação contida no texto da Revista Meio Ambiente Industrial, "Cada brasileiro produz em média $387 \mathrm{Kg}$ de RSU por habitante por ano, o equivalente àquilo que é produzido nos países de renda média/alta [...]”. (RMAI, 2016). Diante do assunto tratado, houve discursos por parte dos participantes da pesquisa de que "as pessoas consomem coisas que não precisam e acham que precisam de muita coisa pra viver" (E5), "Hoje em dia já existe tanto lixo, que até traficam lixo para outros países" (E6). Por conseguinte, a problemática sobre a produção de resíduos sólidos 
Atos de Pesquisa em Educação - ISSN 1809-0354

Blumenau, v.14, n.3, p.1208-1226, set./dez. 2019

DOI: http://dx.doi.org/10.7867/1809-0354.2019v14n3p1208-1226

urbanos (RSU) se constituiu como um motivo para a aprendizagem dos conceitos matemáticos. (MORETTI; SOUZA, 2015).

O objetivo da atividade foi rever o conceito de função, construir o gráfico da função em malha quadriculada e o diagrama de flechas.

$\mathrm{Na}$ fase da inteiração, o problema delimitou-se a determinar a quantidade de resíduos sólidos produzidos por habitante/dia com o intento de representar matematicamente a relação quantidade de habitantes e de resíduos sólidos produzidos (Figura 2).

Figura 2 - Início da construção do modelo matemático.

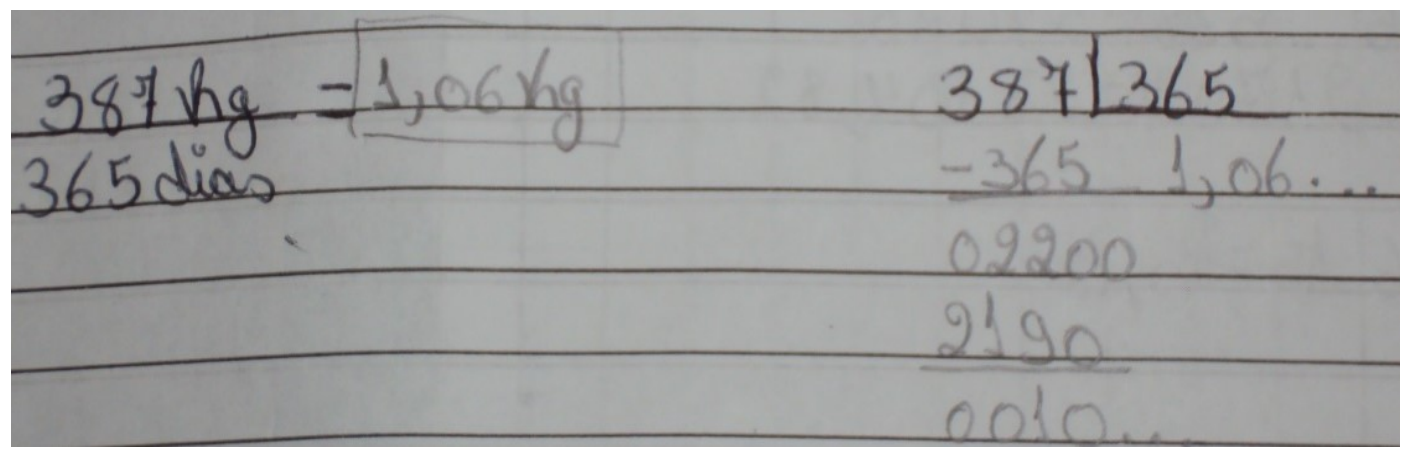

Fonte: Acervo do autor.

Também foi objetivado estimar a quantidade de RSU aproximada produzida pela quantidade de pessoas na família, sala de aula, estudantes da escola e dos habitantes do município, por meio do modelo matemático obtido. Na matematização e resolução, foi estabelecida a hipótese de que é possível estabelecer a relação entre a quantidade de resíduos sólidos produzidos e o número de habitantes. Subsequentemente, os estudantes construíram o gráfico da função e o diagrama de flechas.

Para tratar da Função Afim $f(x)=a x+b$, foi explorada a fatura residencial de energia elétrica dos estudantes. $\mathrm{Na}$ inteiração, o problema foi limitado a analisar a fatura de energia elétrica residencial. Após isso, eles começaram a perceber o quanto gastam com energia elétrica, o que acabou levando à reflexão e, também, a uma preocupação quanto ao gasto com a energia elétrica por parte de alguns participantes da pesquisa, de tal modo que as ações dos estudantes foram estimuladas por um motivo. 
Atos de Pesquisa em Educação - ISSN 1809-0354

Blumenau, v.14, n.3, p.1208-1226, set./dez. 2019

DOI: http://dx.doi.org/10.7867/1809-0354.2019v14n3p1208-1226

Acreditam que precisam de muitos aparelhos elétricos, pois já são dependentes de muitos deles e porque facilitam a vida. Por outro lado, há aparelhos que são comprados, mas que acabam não sendo utilizados, pois não são tão importantes. Comentaram que compram porque acham que irão utilizar (Registro do diário de campo da professora pesquisadora).

"Muitas pessoas são descuidadas, deixam o carregador ligado na tomada sem o celular, lâmpadas acesas durante o dia e a TV geralmente permanece ligada sem ter alguém para assistir. É preciso mais cuidado e iniciativa das pessoas" (E7).

Na matematização e resolução, foi estabelecida a hipótese de que é possível descrever o consumo de energia mensal por meio de uma função a fim de estabelecer uma relação entre as variáveis valor da fatura residencial de energia elétrica e quantidade de energia elétrica consumida no mês.

Após os estudantes terem identificado os elementos da fatura de energia necessários para o cálculo, o modelo matemático foi elaborado com o auxílio da professora (Figura 3).

Figura 3 - Modelo matemático construído por um estudante.

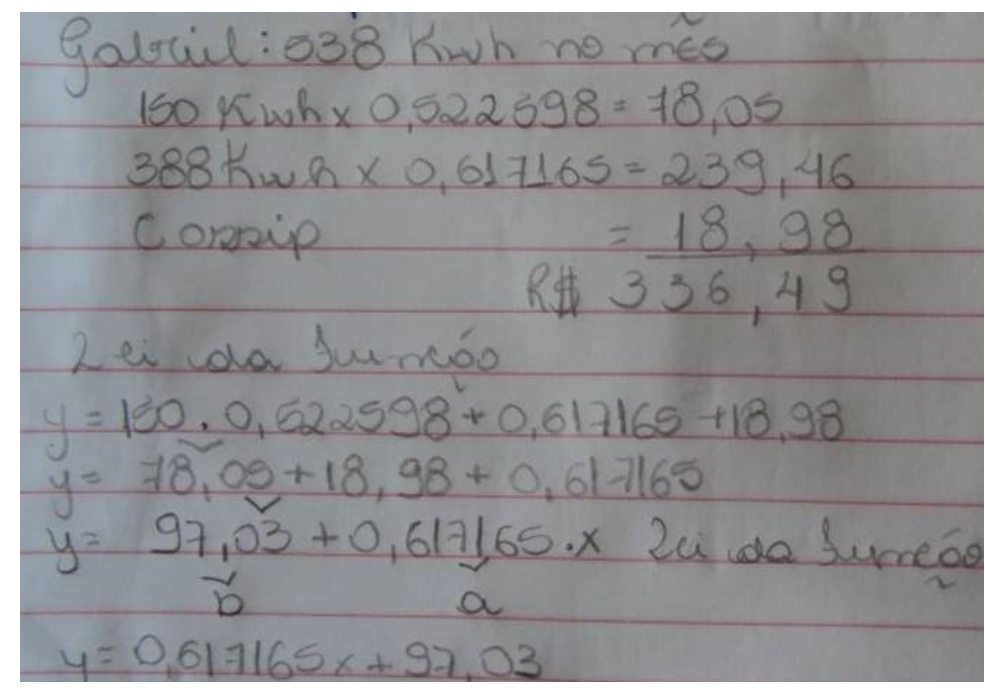

Fonte: Acervo do autor.

O intento da atividade seguinte, caso 2 , foi explorar a fatura residencial de água dos estudantes. Na inteiração, foi explorada a fatura de água residencial e o cálculo do valor da fatura. 
Atos de Pesquisa em Educação - ISSN 1809-0354

Blumenau, v.14, n.3, p.1208-1226, set./dez. 2019

DOI: http://dx.doi.org/10.7867/1809-0354.2019v14n3p1208-1226

Sobre este assunto, os estudantes relataram que a situação em relação ao fornecimento de água no município não é tão boa, pois o Rio Macaco, o qual abastece o município, já está bastante poluído e pelo fato da população já utilizar água do Aquífero Guarani (Registro do diário de campo da professora pesquisadora). Assim, a "mola propulsora", ou seja, o motivo (ALMEIDA; FERRUZZI, 2011) que mobilizou o estudante pode ter sido a preocupação quanto ao uso e/ou fornecimento de água.

Na matematização e resolução foi estabelecida a hipótese de que é possível descrever o consumo de água mensal por meio de uma função linear estabelecendo a relação entre as variáveis valor da fatura residencial de água e quantidade de água consumida no mês.

$\mathrm{Na}$ atividade de modelagem, caso 3, no momento da inteiração, os estudantes fizeram uma visita no barracão de coleta e separação de resíduos sólidos de uma empresa do município (Figura 4).

Figura 4 - Estudantes coletando dados.

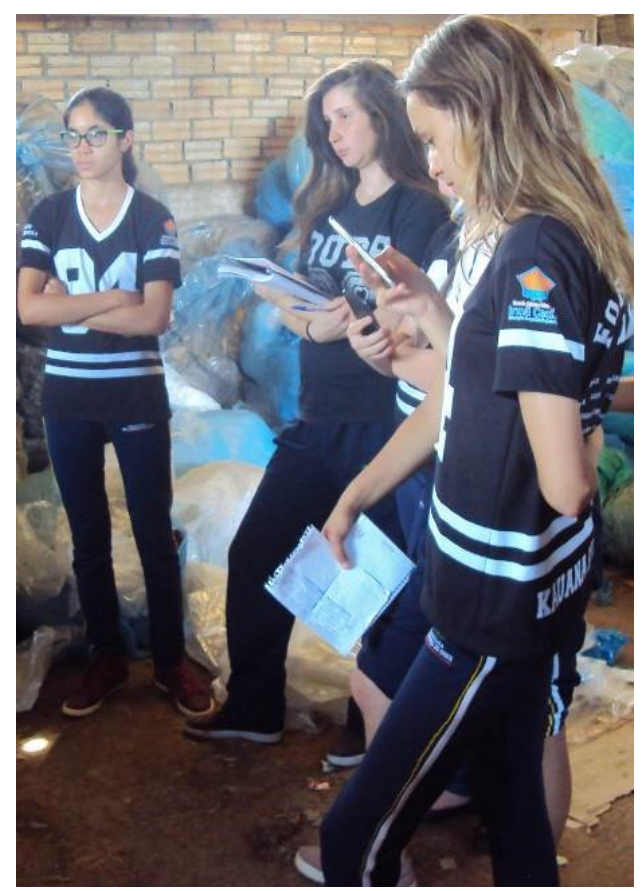

Fonte: Acervo do autor. 
Atos de Pesquisa em Educação - ISSN 1809-0354

Blumenau, v.14, n.3, p.1208-1226, set./dez. 2019

DOI: http://dx.doi.org/10.7867/1809-0354.2019v14n3p1208-1226

O objetivo dessa visita foi para que os estudantes conhecessem como ocorre o processo de coleta e separação de RSU, bem como coletassem informações para a atividade de modelagem. Após a visita houve discussões em sala de aula,

"A coleta de mais materiais para reciclagem tornaria a cidade mais organizada. $\mathrm{O}$ valor pago aos coletores em relação ao seu trabalho é muito baixo, as pessoas sofrem e se empenham para realizar este trabalho, é "vergonhoso", eles estão expostos a vários tipos de doenças" (E8).

Na visita à coletora de resíduos sólidos para reciclagem, muitos estudantes se mostraram interessados, fizeram várias perguntas para os funcionários da empresa. A turma demonstrou bastante empenho e interesse. Trocaram várias ideias no grupo e a maioria conseguiu realizar as atividades (Registro do diário de campo da professora pesquisadora).

O que consta nos registros em diário de campo da professora pesquisadora e das falas dos estudantes mostra que as problemáticas que permearam a atividade de modelagem tais como coleta, separação e venda dos materiais para reciclagem, geraram interesse e curiosidade nos participantes da pesquisa. Desse modo, eles não estavam apenas ocupados com uma atividade escolar, mas estavam tendo a oportunidade, por meio dessa prática pedagógica, para construir e/ou reconstruir o conhecimento de modo coletivo. (BUSTAMANTE, 2016).

$\mathrm{Na}$ resolução e matematização, a partir dos dados coletados, cada grupo de estudantes descreveu a situação-problema e obteve os modelos matemáticos. Ademais, houve a socialização das atividades em sala de aula para promover maior interação entre os estudantes. As atividades restringiram-se a relacionar a quantidade de RSU coletados pela empresa (papelão/plástico/latinhas de alumínio) e o tempo e/ou valor pago pela empresa.

Nas atividades subsequentes, foi explorado o conteúdo Tratamento da Informação (Estatística). Na primeira atividade, caso 1, o objetivo foi introduzir esse conteúdo matemático. Para tanto, foram utilizados dados do relatório de coleta de resíduos sólidos fornecido pela empresa que realiza a coleta de resíduos no município.

$\mathrm{Na}$ inteiração, o problema delimitou-se a investigar os dias da semana em que houve maior percentual de coleta de RSU. Na matematização e resolução, em 
Atos de Pesquisa em Educação - ISSN 1809-0354

Blumenau, v.14, n.3, p.1208-1226, set./dez. 2019

DOI: http://dx.doi.org/10.7867/1809-0354.2019v14n3p1208-1226

um primeiro momento, os dados foram organizados em uma tabela de frequência, na sequência, foram representados em gráficos de colunas e de setores.

A última atividade esteve de acordo com o caso 2 de modelagem. $\mathrm{Na}$ inteiração, os estudantes, organizados em grupos definiram qual integrante do grupo iria se dispor a coletar os dados, que consistia em separar o RSU em sua residência e quantificar por um período de uma semana. Os dados coletados nesse período foram organizados em uma tabela que continha a data e a quantidade de cada tipo de RSU produzido na residência.

Durante a realização das atividades, foi observado que,

Alguns estudantes costumam separar o lixo em casa, outros ainda não. No entanto, utilizam sacola retornável. Acham importante consumir somente o necessário. Comentaram que, no passado, as pessoas produziam menos lixo, pois compravam menos industrializados, existiam menos opções, plantavam seus alimentos e hoje isto já não acontece mais (Registro do diário de campo da professora pesquisadora).

Na matematização e resolução, com as informações registradas em tabela, eles construíram tabelas de frequência e gráficos de colunas e de setores (Figura 5).

Figura 5 - Tabelas e gráficos elaborados pelos estudantes.

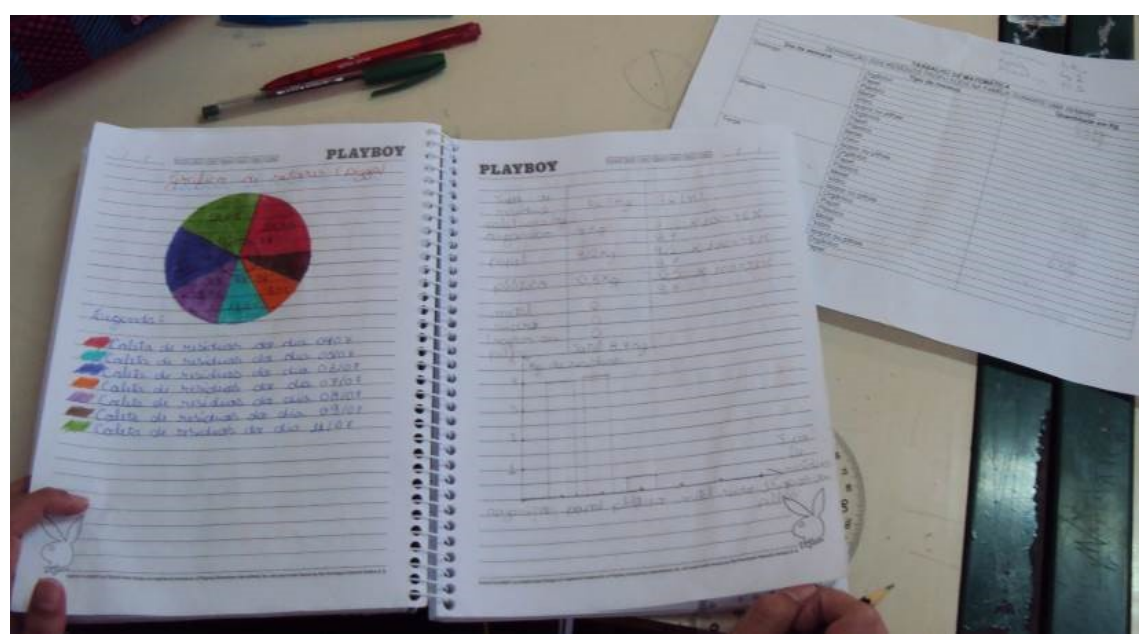

Fonte: Acervo do autor.

Apesar da existência de dificuldade por parte de estudantes quanto à elaboração das atividades de modelagem e quanto à compreensão dos conceitos matemáticos, também houve relatos concernentes à aprendizagem dos conceitos matemáticos e melhoria no processo ensino e aprendizagem, 
Atos de Pesquisa em Educação - ISSN 1809-0354

Blumenau, v.14, n.3, p.1208-1226, set./dez. 2019

DOI: http://dx.doi.org/10.7867/1809-0354.2019v14n3p1208-1226

"Porque o método de aprendizagem é diferente" (E9).

"Fiquei mais interessada em descobrir gastos exagerados, quanto as pessoas consomem" (E10).

"Apresentou de maneira simples e prática como resolver questões em que o tema abordado já era de nosso conhecimento" (E11).

"Eu aprendi equações e estatística. Não sabia nada" (E12).

De maneira semelhante ao que foi mencionado em relação às atividades de modelagem realizadas nos anos iniciais e que foram relatadas na seção 2 deste texto, supomos que as práticas pedagógicas realizadas no $9^{\circ}$ ano do ensino fundamental conduziram os participantes da pesquisa em situação de aprendizagem e, desse modo, a elaboração dos modelos matemáticos necessitaram dos conceitos matemáticos a serem ensinados ou criaram neles a necessidade dos conceitos matemáticos. (MOURA et al., 2010). Assim, em acordo com Moretti e Souza (2015), as práticas pedagógicas possibilitaram a apropriação dos conhecimentos matemáticos, mediante o fazer matemática, ou seja, em atividade.

\section{CONSIDERAÇÕES FINAIS}

Com o objetivo de contribuir para a ampliação da discussão e reflexão do uso da modelagem na prática docente e no processo ensino e aprendizagem da matemática nos anos iniciais e finais do ensino fundamental, este artigo propôs, na forma de hipótese, que a modelagem matemática, na prática pedagógica, pode promover a atividade do estudante, criando nele um motivo especial para sua atividade.

$\mathrm{Na}$ investigação relatada verificou-se que o motivo que permitiu a atividade do estudante, bem como sua estimulação para a ação foi o fato de as práticas pedagógicas de modelagem propostas estarem diretamente relacionadas com 0 cotidiano dos estudantes ou com alguma temática de seu interesse.

Os resultados obtidos demonstraram que os estudantes, por meio do processo de modelagem não permaneceram apenas como receptores de informações, ou seja, dos conteúdos matemáticos. Com efeito, os adolescentes participantes da pesquisa atuaram no seu próprio processo de aprendizagem 
Atos de Pesquisa em Educação - ISSN 1809-0354

Blumenau, v.14, n.3, p.1208-1226, set./dez. 2019

DOI: http://dx.doi.org/10.7867/1809-0354.2019v14n3p1208-1226

apropriando-se de conhecimento matemático. Assim, argumenta-se em favor da plausibilidade da hipótese que orientou este trabalho.

Não obstante, a realização do estudo permitiu verificar que ainda há necessidade de mais pesquisas referentes ao uso da modelagem matemática nos anos iniciais do ensino fundamental, bem como permitiu observar que, na prática pedagógica, a utilização da modelagem ainda não é muito comum nesta etapa do ensino fundamental. Além disso, na disciplina de matemática é frequente a transmissão de uma grande quantidade de informações, conteúdos e exercícios de fixação que acabam impedindo a reflexão e a construção do conhecimento matemático por parte do estudante.

\section{DANIANA DE COSTA}

Professora de Matemática nos Anos Finais do Ensino Fundamental. Licenciada em Matemática pela Universidade Tecnológica Federal do Paraná - UTFPR. Especialista em Educação Matemática: dimensões teórico-metodológicas, pela Universidade Estadual de Ponta Grossa - UEPG. Mestre em Desenvolvimento Regional pela Universidade Tecnológica Federal do Paraná - UTFPR.

\section{EDIVAL SEBASTIÃO TEIXEIRA}

Doutor em Educação pela Universidade de São Paulo - USP. Pós Doutor em Educação pela Universidade Federal do Paraná - UFPR. Pós Doutor em Psicologia Ambiental pela Universidade de Évora (Portugal). Professor do curso de Psicologia e do Mestrado em Desenvolvimento Regional da Universidade Tecnológica Federal do Paraná - UTFPR.

\section{REFERÊNCIAS}

ALMEIDA, L. W. de; SILVA, K. P. da; VERTUAN, R. E. Modelagem Matemática na educação básica. 1ª ed. São Paulo: Contexto, 2012.

ALMEIDA, L. W. de; FERRUZZI, E.C. A comunicação em atividades de Modelagem Matemática: uma relação com a teoria da atividade. In: CONFERÊNCIA INTERAMERICANA DE EDUCAÇÃO MATEMÁTICA, 13ª , 2011, Recife. Anais... Recife: CIAEM, 2011, p. 1-11.

BARBOSA, J. C. Modelagem na Educação Matemática: contribuições para o debate teórico. In: REUNIÃO ANUAL DA ANPED, 24ª , 2001, Caxambu. Anais... Caxambu: ANPED, 2001. p. 1-30. 
Atos de Pesquisa em Educação - ISSN 1809-0354

Blumenau, v.14, n.3, p.1208-1226, set./dez. 2019

DOI: http://dx.doi.org/10.7867/1809-0354.2019v14n3p1208-1226

BIEMBENGUT, M. S.; HEIN, N. Modelagem matemática no ensino. $5^{a}$ edição, São Paulo, Contexto, 2011.

BRAUTIGAM, V. L. L. Modelagem matemática: construindo a interdisciplinaridade. 2001. 75p. Monografia (Especialização Psicopedagogia) - Universidade Estadual do Centro-Oeste do Paraná, Guarapuava, 2001.

BUSTAMANTE, J. E. G. Modelagem Matemática na modalidade online: uma análise segundo a Teoria da Atividade. 215f. Tese (Doutorado em Educação Matemática) Universidade Estadual Paulista "Júlio Mesquita Filho", Rio Claro, 2016.

GASPERIN, I. M. Modelagem matemática: uma metodologia para o ensino de matemática na $3^{a}$ série do $1^{\circ}$ grau. 1990. 36p. Monografia (Especialização em ensino de Matemática e Ciências) - Faculdade Estadual de Filosofia, Ciências e Letras de Guarapuava, 1990.

LEONTIEV, A. N. Uma contribuição à teoria do desenvolvimento da psique infantil. São Paulo: Ícone, 2001.

LOPES, S. R. et al. A construção dos conceitos matemáticos e a prática docente. Curitiba: InterSaberes, 2012. - (Série Matemática em Sala de Aula).

LUNA, A. V. de A.; SOUZA, E. G.; SANTIAGO, A. R. C. M. A Modelagem Matemática nas Séries Iniciais: o gérmen da criticidade. ALEXANDRIA Revista de Educação em Ciência e Tecnologia, v.2, n.2, p.135-157, jul. 2009. Disponível em: <https://periodicos.ufsc.br/index.php/alexandria/article/view/37958/28986>. Acesso em: 11 abr. 2018.

MORETTI, V. D.; SOUZA, N. M. M. de. Educação Matemática nos Anos Iniciais do Ensino Fundamental: princípios e práticas pedagógicas. São Paulo: Cortez, 2015. (Coleção Biblioteca Básica de Alfabetização e Letramento).

MORETTI, V. D.; MOURA, M. O. de. Professores de matemática em atividade de ensino: contribuições da perspectiva histórico-cultural para a formação docente. In:

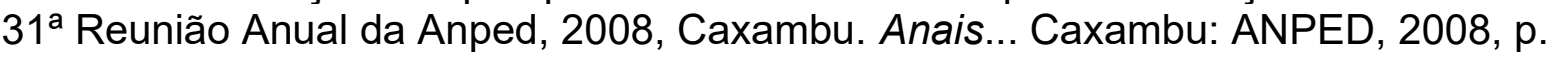
1-18.

MOURA, M. O. de. Educar com a Matemática: saber específico e saber pedagógico. Palestra - Texto 2, p. 1-15. Disponível em:

$<$ https://edisciplinas.usp.br/pluginfile.php/70146/mod_resource/content/1/Texto\%202 $\% 20 \% 20$ MOURA\%2C\%20Manoel\%20Oriosvaldo. \%20Educar\%20com\%20a\%20mat em\%C3\%A1tica.pdf>. Acesso em: 18 abr. 2018.

MOURA, M. O. de et al. Atividade orientadora de ensino: unidade entre ensino e aprendizagem. Revista Diálogo em Educação, Curitiba, v. 10, n. 29, p. 205-229, jan./abr. 2010. Disponível em:

<https://periodicos.pucpr.br/index.php/dialogoeducacional/article/view/3094/3022>. Acesso em: 18 abr. 2018. 
Atos de Pesquisa em Educação - ISSN 1809-0354

Blumenau, v.14, n.3, p.1208-1226, set./dez. 2019

DOI: http://dx.doi.org/10.7867/1809-0354.2019v14n3p1208-1226

QUARTIERI, M. T.; KNIJNIK, G. Modelagem Matemática na escola básica:

surgimento e consolidação. Caderno Pedagógico, Lajeado-RS, v. 9, n. 1, p. 9-26, jan./dez., 2012. Disponível em:

<http://www.univates.br/revistas/index.php/cadped/article/view/842>. Acesso em: 14 mai. 2016.

RMAI - Revista Meio Ambiente Industrial e Sustentabilidade. Brasil gera lixo como primeiro mundo, mas o tratamento ainda é de nação subdesenvolvida. 09 ago. 2016. Disponível em: <http://rmai.com.br/brasil-gera-lixo-como-primeiro-mundo-mas-otratamento-ainda-e-de-nacao-subdesenvolvida>. Acesso em: 09 ago. 2016.

SANTANA, T. S.; BARBOSA, J. A intervenção do professor em um ambiente de Modelagem Matemática e a regulação da produção discursiva dos alunos. Bolema: Boletim de Educação Matemática. Rio Claro - SP, v.26, n. 43, p.991-1020, jul./set., 2012. Disponível em:

<https://www.researchgate.net/publication/314576516_O_significado_em_atividades _de_modelagem_matematica_um_olhar_sobre_pesquisas_brasileiras $>$. Ācesso em: 08 jun. 2016.

SILVA, V. da S. Modelagem Matemática como metodologia para o ensino de Matemática nos anos iniciais: alguns apontamentos sobre a abordagem de conteúdos a partir de relatos de experiências. In: BRANDT, C. et al. (orgs.). Modelagem Matemática: perspectivas, experiências, reflexões e teorizações. Ponta Grossa: Editora UEPG, 2016.

TIDES FOUNDATION. A História das Coisas - documentário com Annie Leonard (The Story of Stuff, 2007). Versão dublada. Disponível em: Acesso em:

<https://www.youtube.com/watch?v=G7_S0mMbKiw>. Acesso em: 19 jun. 2016.

TORTOLA, E.; ALMEIDA, L. M. W. de. Reflexões a respeito do uso da modelagem matemática em aulas nos anos iniciais do ensino fundamental. Revista Brasileira de Estudos Pedagógicos (online), Brasília, v. 94, n. 237, p. 619-642, maio/ago., 2013. Disponível em: <http://www.scielo.br/pdf/rbeped/v94n237/a14v94n237.pdf>. Acesso em: 10 jun. 2016. 